\title{
Vedinpesun onnistuminen automaattisessa lypsyjärjestelmässä - Tekninen onnistuminen ja pesutulos
}

\author{
Anna-Maija Aisla ${ }^{1)}$ ja Mari Hovinen ${ }^{2)}$ \\ ${ }^{1)}$ Agroteknologian laitos, PL 28,00014 Helsingin yliopisto. anna-maija.aisla@helsinki.fi \\ ${ }^{2)}$ Kliinisen eläinlääketieteen laitos, PL 57,00014 Helsingin yliopisto. mari.hovinen@ helsinki.fi
}

\section{Tiivistelmä}

Utareen ja vedinten pinta on merkittävä raakamaidon likaantumisen lähde, joten vedinten pesu ennen lypsyä on tarpeellista maidon likaantumisen ehkäisemiseksi. Maa- ja metsätalousministeriön asetuksen 8/EEO/2002 mukaan vetimet, utareet ja tarvittaessa niiden lähialueet on puhdistettava ja tarvittaessa myös kuivattava ennen lypsyä. Suomessa markkinoilla olevissa automaattisissa lypsyjärjestelmissä ei vielä ole vedinpesun kontrollointia eli pesun epäonnistumisesta ei jää tietoa laitteiston rekisteriin.

Tutkimuksen tavoitteena oli selvittää vedinpesun onnistuminen automaattisessa lypsyjärjestelmässä sekä syitä mahdollisiin epäonnistumisiin. Tutkimuksessa oli mukana kaksi automaattista lypsyjärjestelmää, DeLaval VMS ja Lely Astronaut. Tutkimus tehtiin yhdeksällä suomalaisella automaattilypsyjärjestelmää käyttävällä tilalla.

Vedinten pesun teknistä onnistumista selvitettiin katsomalla onko vedin pesulaitteessa eli tässä tapauksessa pesukupissa (DeLaval) tai harjojen välissä (Lely). Täysin onnistuneessa pesussa vetimen täytyi olla pesulaitteessa kokonaan ja suorana koko pesun ajan. Osittain onnistunut pesu oli kyseessä esimerkiksi silloin, jos vedin oli pesulaittessa vinossa. Täysin epäonnistuneeksi määritellyssä pesussa, vedin ei ollut ollenkaan pesulaitteessa pesun aikana. Tutkimuksessa selvitettiin vedinpesun teknisen onnistumisen lisäksi vedinten pesun pesutulosta. Pesutulosta selvitettiin luokittelemalla vetimet likaisuuden mukaan silmämääräisesti ennen pesua ja pesun jälkeen. Arviointi tehtiin vetimeen koskematta ja vain yhdeltä puolelta. Vetimen pään ja vedinkanavan aukon arvioinnissa apuna käytettiin peiliä. Visuaalisen arvioinnin varmennukseksi vetimistä otettiin puhtausnäytteet pesun jälkeen valkoisilla kuituliinoilla.

Tutkimuksessa mukana olleiden automaattisten lypsyjärjestelmien osalta tulokset ovat melko yhteneväiset. Molemmat järjestelmät onnistuivat kohtuullisesti puhdistamaan sellaiset vetimet, jotka olivat ennen pesua lähes puhtaita tai vain hieman likaisia. Sellaisten vedinten kohdalla, jotka ennen pesua olivat likaisia tai erittäin likaisia, molemmilla järjestelmillä oli vaikeuksia saada vetimiä täysin puhtaiksi. Parantamisen varaa löytyy myös vedinten pesun teknisen onnistumisen osalta. Lehmästä johtuvia syitä vedinpesun epäonnistumiseen oli muun muassa huono utarerakenne ja rauhaton käytös pesun aikana.

Tulosten perusteella voidaan todeta, että eläinten puhtaana pysymiseen on automaattilypsyssä kiinnitettävä tavallista enemmän huomiota. Automaattinen lypsyjärjestelmä vaatiikiin karjanhoitajalta aktiivisuutta, jotta vedinten pesu onnistuisi ja lypsy tapahtuisi puhtaista vetimistä. Laitevalmistajan osuudeksi jää laitteiston toimintavarmuuden parantaminen

\section{Asiasanat}

Automaattinen lypsy, lypsyhygienia, vedinpesu, vedinpesun onnistuminen 


\section{Johdanto}

Utareen ja vedinten pinta on merkittävä raakamaidon likaantumisen lähde, joten vedinten pesu ennen lypsyä on tarpeellista maidon likaantumisen ehkäisemiseksi. Maa- ja metsätalousministeriön asetuksen 8/EEO/2002 mukaan vetimet, utareet ja tarvittaessa niiden lähialueet on puhdistettava ja tarvittaessa myös kuivattava ennen lypsyä (MMM 2002). Suomessa markkinoilla olevissa automaattisissa lypsyjärjestelmissä ei vielä ole vedinpesun kontrollointia eli pesun epäonnistumisesta ei jää tietoa laitteiston rekisteriin.

Automaattilypsyyn siirryttäessä on havaittu muutoksia maidon laadussa. Merkittävimmät muutokset on havaittu maidon solupitoisuuksissa, bakteerimäärissä, vapaissa rasvahapoissa ja maidon jäätymispisteessä. Suomessa automaattilypsytiloilla maidon laatu on ollut keskimäärin hieman heikompaa kuin muilla tiloilla, mutta maito on kuitenkin selkeästi parhaassa laatuluokassa eli E-luokassa. (Maitohygienialiitto 2004).

Vedinpesun pääasiallisena tarkoituksena on vedinten puhdistaminen liasta, joka voi pilata maidon laatua. Automaattisessa lypsyjärjestelmässä ei ole sensoreita, jotka havainnoisivat, kuinka likainen vedin on pesuvuorossa. Pesujärjestelmän toiminta perustuukin oletukseen, että kaikki vetimet ovat yhtä likaisia/puhtaita. Lian poistamisen lisäksi vedinpesulla on toinenkin tärkeä tehtävä, maidonvirtauksen stimulointi (de Koning ym 2002).

Automaattisen lypsyn myötä yhä tärkeämmäksi asiaksi on noussut lehmien puhtaus. Yleisesti todettuja lehmien puhtaanapitoon vaikuttavia tekijöitä ovat parsien kuivittaminen ja utarekarvojen ajelu. Pesuyksikön harjojen tai vedinkumin vaihtaminen säännöllisin ja riittävän lyhyin välein on tärkeää hyvän pesutehon kannalta. Lypsytiheydellä on myös vaikutusta vedinpuhtauteen. Mitä useammin ja säännöllisemmin lehmät käyvät lypsyllä, sitä useammin vetimet myös pestään, jolloin lika ei pääse pinttymään vetimiin. Makuuparsien määrä, ominaisuudet ja puhtaus vaikuttavat monella tapaa vedinten puhtauteen. Jos makuuparsien lukumäärä lehmää kohti on alhainen $(<1)$, vedinten likaantumisen riski kasvaa. Parren oikealla koolla ja rakenteilla voidaan vähentää lehmien makaamista käytävällä, jossa myös utareet ja vetimet likaantuvat helposti. Sorkkien kunto vaikuttaa myös yllättävän paljon vedinten puhtauteen. Lehmät, joilla on huono sorkkaterveys, likaavat utareensa helpommin kuin lehmät, joiden sorkkaterveydessä ei ole huomautettavaa. Syynä on pidempiaikainen makuulla olo ja vaikeudet makuulle käydessä ja ylös noustessa, minkä seurauksena utareet joutuvat enemmän kosketuksiin jalkojen ja sorkkien kanssa. (Knappstein ym 2004).

Tutkimus tehtiin osana laajempaa automaattilypsyä koskevaa tutkimusta. Helsingin yliopiston eläinlääketieteellisessä tiedekunnassa on meneillään tutkimus eroteltavan maidon ja utaretulehduksen havaitsemisesta sekä vedinpesun onnistumisesta ja tehokkuudesta automaattisessa lypsyjärjestelmässä. Tutkimuksen tavoitteena oli selvittää vedinpesun onnistuminen automaattisessa lypsyjärjestelmässä sekä syitä mahdollisiin teknisiin epäonnistumisiin vedinten pesussa. Teknisen onnistumisen lisäksi tavoitteena oli selvittää pesujen pesutulos eli kuinka hyvin laitteisto teknisesti onnistuessaan puhdistaa vetimen.

\section{Aineisto ja menetelmät}

Tutkimuksessa oli mukana molemmat Suomessa tutkimuksen suunnittelun aikana (2003) käytössä olleet automaattiset lypsyjärjestelmät, ruotsalainen DeLaval VMS ja hollantilainen Lely Astronaut. DeLavalin VMS pesee vetimet erillisellä pesuyksiköllä. VMS paikantaa vetimet vedinpesun yhteydessä. VMS:n pesukuppi pesee vetimet lämpimällä vedellä käyttäen apuna ilmanpainetta. Pesukuppi myös kuivaa vetimet ilmalla pesun jälkeen ja ottaa alkusuihkeet. Lely Astronautissa vedinten pesu tapahtuu kahden pyörivän ja kostean harjan avulla. Erillistä vedinten kuivausta järjestelmässä ei ole. Vetimet pestään Lelyn suosituksen mukaan kahdella harjauskerralla. Vetimiä ei paikanneta ennen pesua, vaan paikannukseen käytetään edellisen lypsyn koordinaatteja.

Tutkimuksen aineisto kerättiin syksyllä 2003. Tutkimuksessa oli mukana 9 tilaa, joista neljällä on käytössä Lely Astronaut ja viidellä DeLavalin VMS. Vedinpesujen teknistä onnistumista selvitettiin katsomalla onko vedin pesulaitteessa eli tässä tapauksessa pesukupissa (DeLaval) tai harjojen välissä (Lely). Pesun onnistuminen katsottiin vedinkohtaisesti. Onnistuneessa pesussa vetimen täytyi olla pesulaitteessa kokonaan ja suorana koko pesutapahtuman ajan, molemmilla harjauskerroilla Lelyn kyseessä ollessa. Tulokset kirjattiin ylös sen mukaan oliko kyseessä onnistunut pesu, osittain onnistunut pesu vai epäonnistunut pesu. Osittain onnistunut pesu oli kyseessä esimerkiksi silloin, jos vedin oli 
pesulaittessa vinossa. Täysin epäonnistuneeksi määritellyssä pesussa, vedin ei ollut ollenkaan pesulaitteessa pesun aikana.

Vedinpesun pesutulos selvitettiin luokittelemalla teknisesti onnistuneesti pestyt vetimet likaisuusasteen mukaan. Vedinten likaisuus arvioitiin silmämääräisesti sekä ennen pesua että pesun jälkeen. Silmämääräinen vedinten puhtauden arviointi tehtiin vedinkohtaisesti vetimeen koskematta. Vedinten likaisuus katsottiin vain yhdeltä puolelta. Vetimen pään ja vedinkanavan aukon likaisuus katsottiin peilin avulla. Likaisuusasteen ja lian paikan lisäksi eroteltiin lian laatu. Lika luokiteltiin laadullisesti joko lannaksi tai kuivikkeeksi.

Visuaalisen arvioinnin varmennukseksi vetimistä otettiin puhtausnäytteet pesun jälkeen. Puhtausnäytteet otettiin valkoisilla kuituliinoilla. Puhtausnäyte otettiin siten, että liina laitettiin koko vetimen ympärille ja vedettiin kerran ylhäältä alas. Puhtausnäytteet otettiin kahdesta näytteidenottajaa lähimmästä vetimestä eli yhdestä etu- ja takavetimestä.

\section{Tulokset ja tulosten tarkastelu}

Lelyn kohdalla 85,0 \% vetimistä oli pesulaitteessa oikein, DeLavalilla luku oli 79,9\% (p = 0,012). Vastaavat lehmäkohtaiset luvut ovat Lelyllä $60,7 \%$ ja DeLavalilla $57,1 \%$. Vedinten pesun teknisessä onnistumisessa oli vaihtelua tilojen välillä. DeLavalin tiloilla tekniset onnistumisprosentit olivat 62.9 \%:n ja $95.8 \%$ :n välillä. Lelyn tiloilla vaihtelu oli $80.4 \%$ :sta $89.9 \%$ :in. Lelyn tiloilla $63 \%$ osittain epäonnistuneista ja $80 \%$ täysin epäonnistuneista pesuista epäonnistui molemmilla harjauskerroilla.

Tilojen välillä erot pesun teknisessä onnistumisessa vaihtelivat paljon. Vaihtelua oli enemmän tilojen välillä kuin robottimerkkien välillä. Oikeissa olosuhteissa onkin mahdollista päästä lähelle teknisesti täydellisesti onnistunutta vedinten pesua.

Lehmän rauhaton käyttäytyminen pesutilanteessa aiheutti ongelmia erityisesti Lelyn kohdalla, koska Lelyn pesulaite pesee vetimet edellisen lypsyn vedinten paikkakoordinaattien mukaan. Utarerakenne aiheutti molemmilla roboteilla ongelmia. DeLavalin pesulaitteen toimintaa voi vaikeuttaa utarekarvat, jotka saattavat aiheuttaa epäonnistuneen vetimen paikannuksen. Keskimäärin noin puolet kaikista teknisesti epäonnistuneista pesuista jäi ilman selkeää ulkopuolista syytä epäonnistumiseen. Toisin sanoen puolet epäonnistumisista voidaan katsoa johtuneeksi laitteiston epävarmasta toiminnasta. (Taulukko 1).

Taulukko 1. Vedinten pesun teknisen epäonnistumisen syyt.

\begin{tabular}{llcccccc}
\hline & Pesu & $\begin{array}{c}\text { Yhteensä } \\
(\mathrm{kpl})\end{array}$ & $\begin{array}{c}\text { Utare- } \\
\text { rakenne }\end{array}$ & $\begin{array}{c}\text { Lehmän } \\
\text { käytös }\end{array}$ & $\begin{array}{c}\text { Utare- } \\
\text { karvat }\end{array}$ & $\begin{array}{c}\text { Tekninen } \\
\text { vika }\end{array}$ & $\begin{array}{c}\text { Ei syy- } \\
\text { tä }\end{array}$ \\
\hline DeLaval & Osittain onnistunut & 76 & $14 \%$ & $12 \%$ & $9 \%$ & $0 \%$ & $65 \%$ \\
& Epäonnistunut & 44 & $7 \%$ & $7 \%$ & $0 \%$ & $52 \%$ & $34 \%$ \\
Lely & Osittain onnistunut & 76 & $25 \%$ & $21 \%$ & $0 \%$ & $0 \%$ & $54 \%$ \\
& Epäonnistunut & 31 & $6 \%$ & $52 \%$ & $0 \%$ & $0 \%$ & $42 \%$ \\
& & & & & & & \\
& & & & & & & \\
& & &
\end{tabular}

Vedinpesun pesutulos kuvaa pesulaitteen kykyä puhdistaa vedin liasta. Pesutuloksen määrittämisessä on otettu huomioon vain onnistuneet pesut. Saatujen tulosten mukaan DeLavalin tiloilla ennen pesua likaisuusasteeltaan luokkaan 1 luokitelluista vetimistä suurin osa $(64,6 \%)$ puhdistui pesussa täysin. Kaikkien muiden likaisuusasteiden osalta suurin osa vetimistä oli pesun jälkeen luokassa 1 eli ne olivat lähes puhtaita. Ennen pesua erittäin likaisista vetimistä vain 11,6 \% puhdistui kokonaan ja jopa 20,1 \% jäi likaisuusasteeltaan luokkaan 2. (Kuvio 1). 


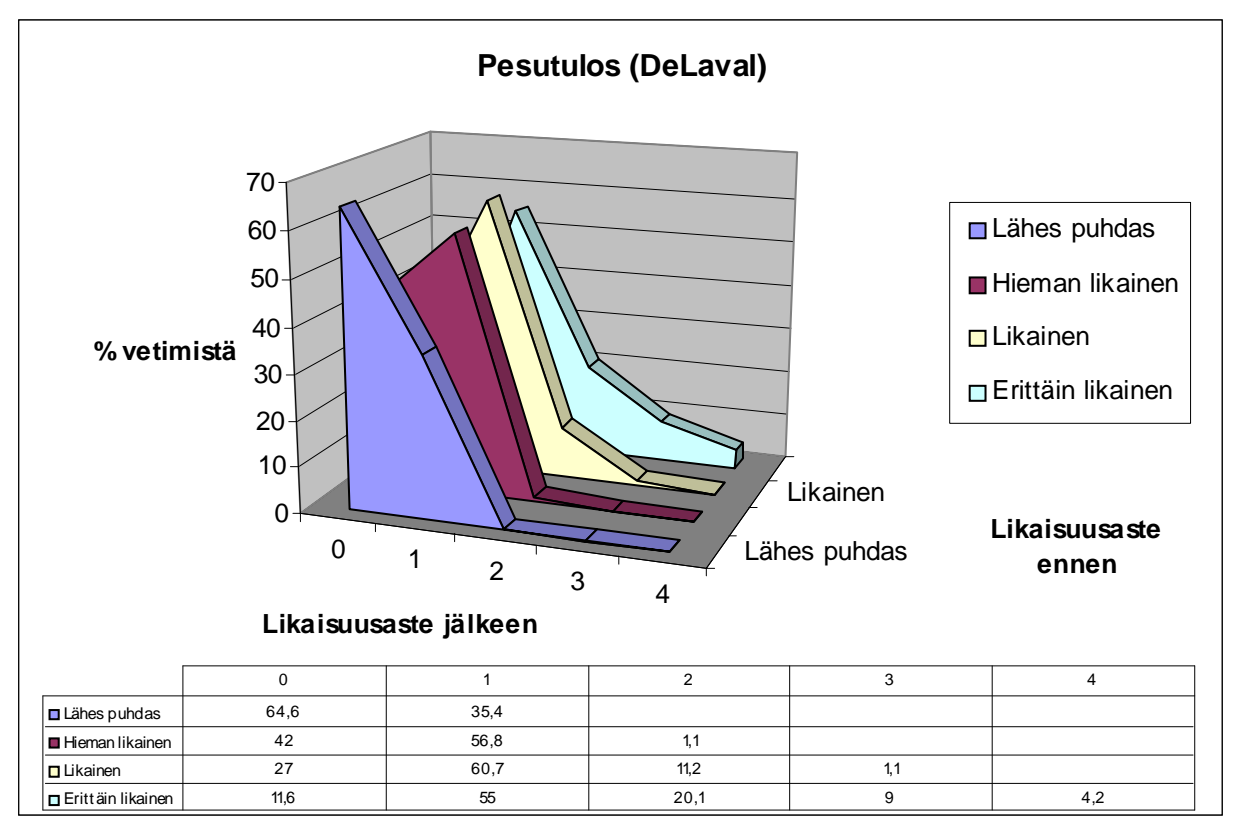

Kuvio 1. Vedinten pesun pesutulos DeLaval VMS -järjestelmissä

Lelyn kohdalla vain ennen pesua likaisuusasteeltaan luokassa 1 olleista vetimistä suurin osa $(53,9 \%)$ puhdistui pesussa kokonaan (kuvio 2). Ennen pesua vedinten luokkaa 1 suurempi likaisuusaste aiheutti laitteelle vaikeuksia saada vetimet täysin puhtaiksi. Erittäin likaisista vetimistä vain 13,6 $\%$ puhdistui kokonaan. Erittäin likaisten vedinten puhdistaminen näyttäisi tuottavan ongelmia, sillä jopa $31,4 \%$ jäi luokkaan 2 ja 12,4 \% luokkaan 3. Kuviosta 2 nähdään, että ennen pesua luokassa 1 olleista vetimistä $1,4 \%$ on ollut pesun jälkeen luokassa 2 . Syynä likaisuuden lisääntymiseen pesussa voi olla likaisen pesulaitteen levittämä lika tai tarkkailijan arviointivirhe.

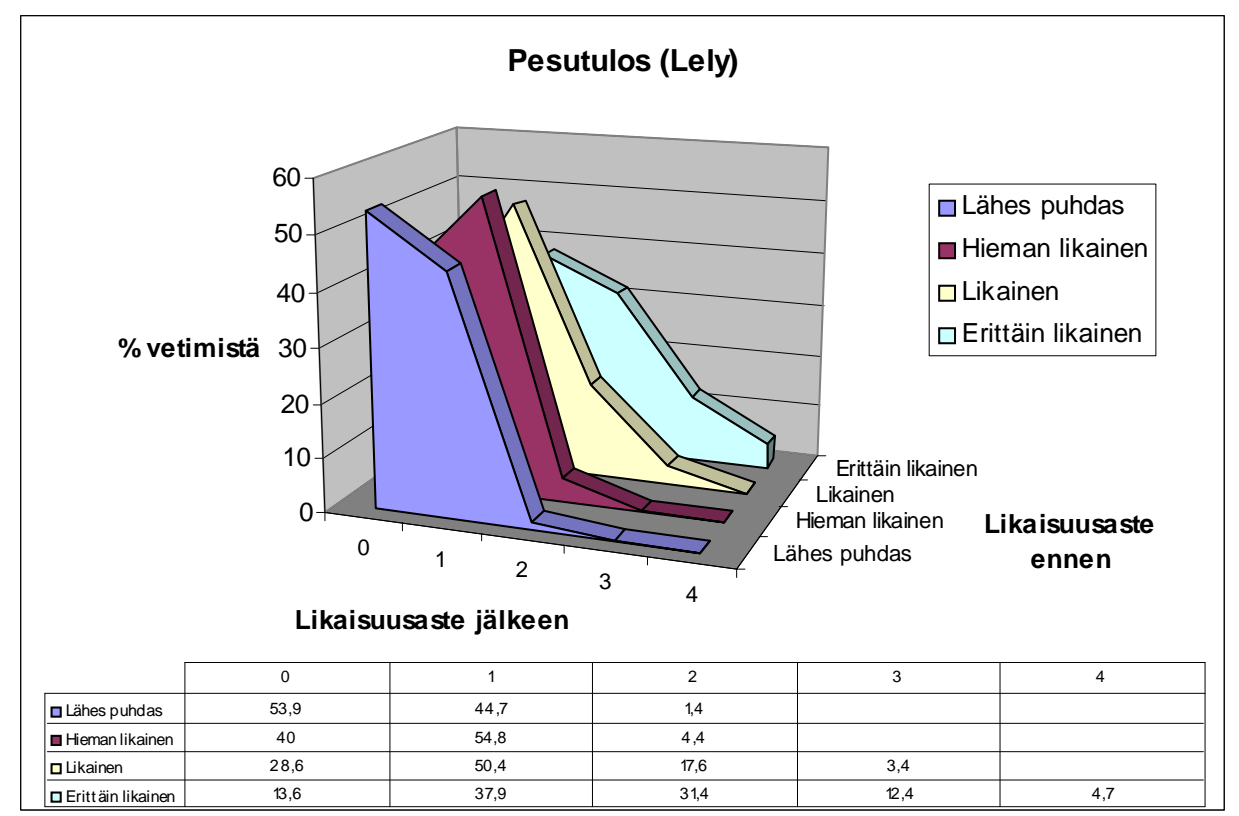

Kuvio 2. Vedinten pesutulos Lely Astronaut -järjestelmissä.

Pesun jälkeen likaa jäi molemmilla järjestelmillä useimmiten vetimen runkoon. Lian määrää ei voida määritellä erikseen vetimen eri osille, vaan esimerkiksi vetimen rungossa on voinut olla vain pieni likatäplä. Vedinkanavan aukko jäi yllättävän useasti likaiseksi. Vetimet puhdistuivat paremmin kuivikkeesta kuin lannasta. (Kuvio 3). 


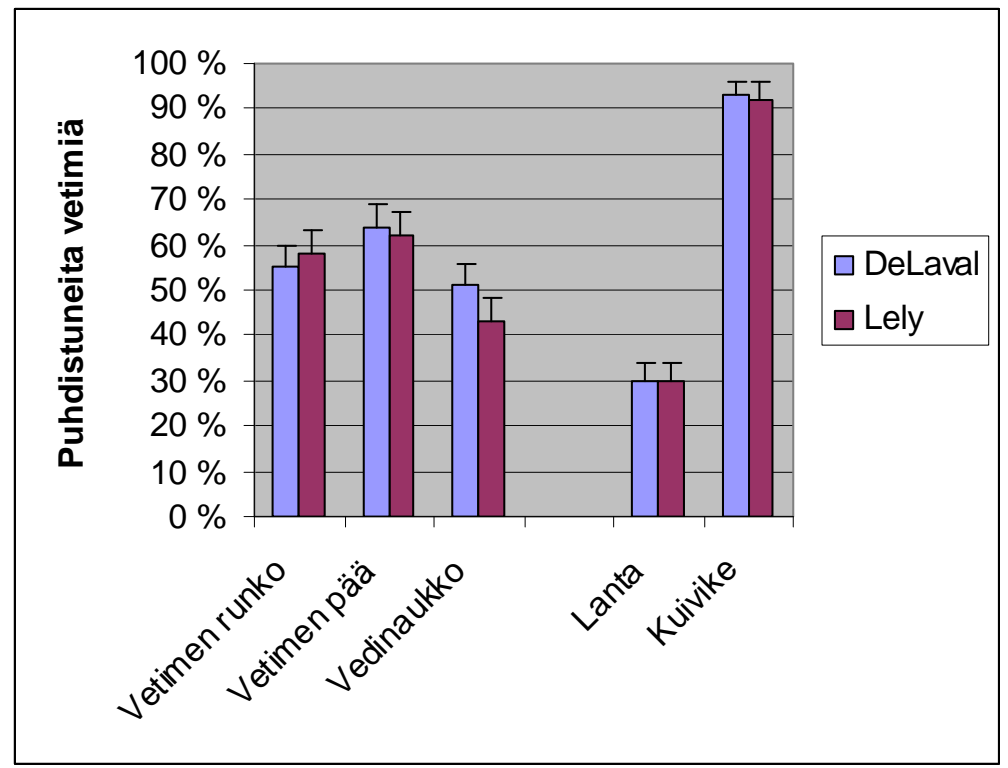

Kuvio 3. Vetimen eri osien puhdistuminen pesussa ja vetimen puhdistuminen lannasta ja kuivikkeesta.

Tulosten perusteella voidaan todeta, että molemmat pesulaitteet onnistuivat kohtuullisesti puhdistamaan sellaiset vetimet, jotka olivat ennen pesua lähes puhtaita tai vain hieman likaisia. Sellaisten vedinten kohdalla, jotka ennen pesua olivat likaisia tai erittäin likaisia, molemmilla pesulaitteilla oli vaikeuksia saada vetimiä täysin puhtaiksi.

\section{Johtopäätökset}

Vedinpesun teknisen onnistumisen kannalta kriittisiä tekijöitä ovat lehmän utarerakenne, lehmän käyttäytyminen pesun aikana sekä vedinkoordinaattien oikeellisuus. Jos nämä edellä mainitut asiat ovat kunnossa, laitteella on aina paremmat mahdollisuudet onnistua vedinten pesussa. Teknisen onnistumisen kannalta onkin olennaista, että laitteen käyttäjä huolehtii utarerakenteen muuttumisen seuraamisesta lypsykauden eri vaiheissa ja säätää tarvittaessa laitteistoa. Myös utarekarvojen ajeleminen ja laserin puhtaudesta huolehtiminen ovat erittäin tärkeitä laitteiston toiminnan ja lypsyhygienian kannalta. Tilalla vedinpesun onnistumista kannattaa seurata aika ajoin, jotta tiedetään millainen tilanne omalla tilalla on ja onko tilanteeseen tarpeen reagoida.

Vedinpesun tekninen onnistuminen ei kuitenkaan takaa vedinten puhdistumista pesussa. Jos vetimessä on pinttynyttä likaa, laitteilla on huomattavia vaikeuksia saada vetimiä puhtaiksi. Puhdistuvuuden kannalta ongelmia aiheuttavat myös huonokuntoiset vetimet. Hoitaja voi vaikuttaa vedinpuhtauteen huolehtimalla navetan ja erityisesti makuuparsien sekä robotin puhtaudesta. Vedinten likaantumisen ennaltaehkäisyn merkitys korostuu automaattisessa lypsyjärjestelmässä.

Automaattinen lypsyjärjestelmä on yhä useamman tilan valinta. Järjestelmä vaatii kuitenkin erityistä aktiivisuutta hoitajan osalta, jotta lypsy tapahtuisi puhtaista vetimistä. Järjestelmässä itsessäänkin on vielä parantamisen varaa, joten pelkästään hoitajan vastuulla vedinpuhtaus ei ole. Suuri vastuu sekä vedinpesun teknisen onnistumisen varmentamiseksi että hyvän pesutuloksen saavuttamiseksi on laitevalmistajilla. 


\section{Kirjallisuus}

de Koning, K., van der Vorst, Y. \& Meijering, A. 2002 Automatic milking experience and development in Europe. Teoksessa The first automatic milking conference on robotic milking. Wageningen pers. Osa I s. 1-11.

Hovinen, M., Aisla, A-M. \& Pyörälä S. 2005. Visual detection of technical success and effectiveness of teat cleaning in two automatic milking systems. J. Dairy Sci. 88. p. 3354-3362.

Knappstein, K., Roth,N., Slaghuis, B. ,Ferwerda-van Zonneveld, R., Walte, H-G.\& Reichmuth, J. 2004. Farm hygiene and teat cleaning requirements in automatic milking. Teoksessa Automatic milking: a better understanding. Wageningen Academic Publishers. s. 83-93.

Maa- ja metsätalousministeriö. 2002. Maidontuotantotilojen hygienia. Asetus 8/EEO/2002. [Viitattu 30.11.2005] Saatavissa www-muodossa:

< URL: http://www.mmm.fi/el/laki/k/k15fi.pdf

Maitohygienialiitto. 2004. Maitohygienialiiton keräämää tietoa tuottajamaidon laadusta. [Viitattu 30.11.2005] Saatavissa www-muodossa:

<URL: http://www.maitohygienialiitto.fi/tietoa_maidon_laadusta_04.html 